\title{
Moments, not minutes: The nature-wellbeing relationship
}

\author{
Miles Richardson · Holli-Anne Passmore · Ryan Lumber \\ Rory Thomas · Alex Hunt
}

\begin{abstract}
A wealth of literature has evidenced the important role that the greater-than-human natural environment plays in our mental health and wellbeing (reviews by Bratman et al., 2019; Capaldi et al., 2014, 2015; Pritchard et al., 2019). Spending time in nature, engaging with nature directly and indirectly, and a strong sense of nature connectedness (a psychological/emotional connection with nature) have each been shown to positively impact well-being. Few studies, however, have examined the importance that various nature-related factors have on our well-being when examined in concert with each other, and no studies have simultaneously examined the differential influences of nature connectedness and engagement. In the current study, using a national United Kingdom sample of 2,096 adults, we provide new insights into this gap in the literature. Our primary focus was on examining, when considered simultaneously, the patterns and relative predictive importance to hedonic wellbeing (i.e., happiness), eudaimonic wellbeing (i.e., worthwhile life), illbeing (i.e., depression and anxiety), and general physical health of five nature-related factors: (1) nature connectedness, (2) time in nature, (3) engagement with nature through simple everyday activities, (4) indirect engagement with nature, and (5) knowledge and study of nature. A consistent pattern of results emerged across multiple analytical approaches (i.e., correlations, linear regression, dominance analyses, commonality analysis), wherein time in nature was not the main (or significant) predictive nature-related factor for wellbeing. Rather, nature connectedness and engaging with nature through simple activities (e.g., smelling flowers) consistently emerged as being the significant and prominent factors in predicting and explaining variance in mental health and wellbeing. Implications for practical application and policy/programme planning are discussed.
\end{abstract}

Keywords: nature connectedness; time in nature; well-being; simple activities; happiness; worthwhile life; wellbeing

\section{Introduction}

Mental health is a global issue of concern. It is estimated that $30 \%$ of the population worldwide suffers from a mental disorder (Steel et al., 2014), with more than 264 million people affected by depression, and more than 284 million affected by anxiety (Global Burden of Diseases, [GBD] 2017). Of course, complete mental health is not merely the absence of illbeing; it is also the presence of wellbeing (Jahoda, 1958; Keyes, 2005; WHO, 2018), both hedonic (e.g. happiness) and eudaimonic (e.g., feeling that life is worthwhile/having meaning in life) (Lambert et al., 2015; Ryan et al., 2008).

The important role that the natural environment plays in maintaining and enhancing our

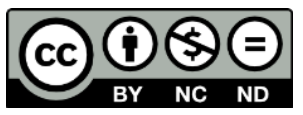

Copyright belongs to the author(s) www.internationaljournalofwellbeing.org 
mental health and wellbeing has been well established through a wealth of consistent evidence (see reviews Bratman et al., 2019; Capaldi et al., 2014; Capaldi et al., 2015, Howell \& Passmore, 2013; Pritchard et al., 2019). Indeed, a close relationship with nature has been put forth as a basic human psychological need that must be satisfied to experience complete wellbeing (Baxter \& Pelletier, 2019; Hurly \& Walker, 2019). Empirical studies have evidenced that time in nature, direct and indirect contact with nature, engaging with nature through simple activities (i.e., sitting in a garden, smelling wildflowers; Bowler et al., 2010; McMahan \& Estes, 2015; Passmore \& Howell, 2014), and increased nature connectedness (i.e., a psychological / emotional connection with nature; McEwan et al., 2019) are beneficial to wellbeing. Yet, we are not aware of any studies that have examined these factors in concert with each other, in the same study or with a large national data set. This is important as the benefits of individual factors such as 'dosage' of time in nature (White et al., 2019) can drive policy, public perception (and individual practitioners) towards a focus solely on this one factor alone (time and exposure), rather than a more rounded approach (Natural England, 2020) whilst largely disregarding other factors such as nature connectedness. Thus, to address this gap, in the current study we examined the predictive importance to mental health and wellbeing of five nature-related factors (nature connectedness, time in nature, engagement with nature through simple activities, indirect engagement with nature, and knowledge and study of nature). We also examined the predictive importance to general physical health of these five nature-related factors.

Systematic meta-analyses have evidenced that people who have a higher level of nature connectedness tend to have higher levels of both hedonic (positive affect, happiness, satisfaction with life) and eudaimonic (positive relations with others, autonomy, meaning in life, competence, personal growth, vitality) wellbeing (respectively Capaldi et al., 2014; Pritchard et al., 2019). Moreover, nature relatedness (akin to nature connectedness) has been evidenced to significantly and distinctly predict wellbeing over and above how generally connected people feel to family and friends (Zelesnki \& Nisbet, 2014). Indeed, in light of this cumulative evidence, a call has been made for the Gallup World Poll to include nature connectedness as an important item by which to measure wellbeing on a global scale (Lambert et al., 2020).

The research into nature connectedness builds on a broad base of research demonstrating that exposure to nature provides a myriad of wellbeing benefits. Some of this work, utilizing epidemiological data, has examined the positive link between general health and the presence of local greenspace and incidental contact with nature (e.g., Verheij et al., 2008; Van den Berg et al., 2010). Other work has demonstrated how visits to and time spent in nature impact mental wellbeing (e.g. Meredith et al., 2020; White et al., 2019). Even indirect contact with naturetechnologically-mediated nature via virtual-reality immersive experiences, watching nature documentaries, or even simply viewing slideshows/photos of nature-has been shown to be good for our mental health (Beukeboom et al., 2012; Keltner et al., 2017; Tanja-Dijkstra et al., 2017; White et al., 2018; see also reviews noted above); albeit, exposure to live nature has a stronger beneficial effect. Interestingly, contrary to Keltner and colleagues' findings regarding boosts to positive emotions subsequent to watching nature documentaries, Martin and colleagues (2020) reported a negative association between watching/listening to nature programmes and wellbeing. They surmised this could be a function of nature documentaries increasingly featuring information on environmental degradation, which could cause individuals highly connected to nature to feel less satisfied with life.

Knowledge of and studying nature can also be considered a form of indirect engagement. There are few studies looking specifically at the relationship between knowledge and study of the natural world and wellbeing. However, the one study we found which did explore this found 
a positive connection. In a longitudinal study over a fall semester, Nisbet and colleagues (2011) found that students taking nature-based courses (biology, environmental studies, earth sciences, geography) reported significantly higher levels of vitality at the end of the semester than did the control group of students taking non-nature-based courses. Mediation analyses, though, revealed that this increase in vitality was a function of enhanced nature relatedness, rather than a direct effect of knowledge and study alone.

However, despite the clear beneficial role that nature plays in our wellbeing, several signs indicate that as a society, we have become disconnected from nature. Culturally, references to nature in fiction, songs, and movie storylines have been steadily declining since the 1950s (Kesebir \& Kesebir, 2017). A 2017 Wildlife Trusts study of 2,000 British adults found that $70 \%$ of respondents reported that they had "lost touch with nature"; that same study found that $37 \%$ of parents said their knowledge of nature was too sparse for them to teach their children about common trees or animals such as identifying an oak tree or a barn owl. In a 2020 National Trust survey, around $80 \%$ of people reported that they rarely or never watched wildlife, smelled wildflowers, or drew/photographed nature; $62 \%$ of people rarely or never listed to bird song or took a moment to mark natural cycles such as the vernal equinox (National Trust, 2020). The crises of a warming climate and biodiversity loss are further indicators of a disconnect and failing relationship with nature. Over time we are accepting increasingly degraded natural environments as "normal", a phenomenon that Peter Kahn (1999) has dubbed "environmental generational amnesia". Thus, now, perhaps more than ever, studies are needed which highlight the benefits of a strong relationship with nature, and the role that nature plays in a happy and worthwhile life.

Recently, research has demonstrated the benefits to mental health and wellbeing of noticing the simple things in everyday nature. McEwan and colleagues (2019) found that when individuals were prompted to notice the good things in urban nature, mental health not only improved significantly in the general population, clinically significant increases in mental health were evidenced in a sample of those with mental health difficulties. Further analyses (McEwan et al., 2020) revealed the simplicity of these interactions with everyday urban nature that had boosted mental wellbeing (e.g., appreciation of street trees, flowering plants, green planting amidst built space, awe at colourful/dramatic skies). Passmore and Holder (2017) found that participants who had been randomly assigned to notice everyday nature and note what emotions were evoked, reported significantly higher levels of positive affect, feelings of elevation, and a general sense of connectedness at the end of two weeks compared to those in control groups. Moreover, the wellbeing benefits of noticing everyday nature emerged even though participants who noticed nature had not spent significantly more time in nature than did their counterparts in control conditions.

While numerous studies have examined the bivariate relationship between wellbeing and a single nature-factor-such as time in nature, indirect contact with nature, or nature connectedness - few studies have looked at the relationship between wellbeing and several nature-related factors considered in concert with each other. Martin and colleagues (2020), though, took a welcome step in this direction in their examination of how nature connectedness and nature contact predicted the outcomes of wellbeing, and pro-environmental behaviours. They noted that previous research evidencing the importance of time in nature have not also considered individual factors such as levels of nature connectedness (e.g., Meredith et al., 2020; White et al., 2019).

To help address this gap in the literature, in the current study utilizing a large UK-based population sample, we considered how five nature-related factors-nature connectedness, time 
in nature, engagement with nature through simple activities, indirect engagement with nature, and knowledge/study of nature-individually and simultaneously relate to outcomes of hedonic wellbeing (i.e., happiness), eudaimonic wellbeing (i.e., worthwhile life), illbeing (i.e., depression and anxiety), and general physical health.

In addition to nature, two facets that experts agree are core to mental health are autonomy (i.e., a sense that one has control over one's life) and relatedness (i.e., feeling that one is connected to a larger circle) (Manwell et al., 2015). Decades of research have evidenced a link between wellbeing and feeling a sense of autonomy or control over one's life (e.g., Inglehart et al., 2008; Lachman \& Weaver, 1998; Reis et al., 2000; Ryan et al., 2008; Verne, 2009). For example, autonomy is negatively related to depression (Kim \& Fusco, 2015; Mirowsky \& Ross, 1990; Steptoe et al., 2007) and positively related to positive affect and life satisfaction (Helzer \& Jayawickreme, 2015; Welzel \& Inglehart, 2010), in addition to being positively correlated to meaning in life and feeling that life is worthwhile (Costin \& Vignoles, 2019; Martela et al., 2018).

Similarly, an abundance of research has evidenced the clear impact that satisfaction of our basic relatedness need has on our overall happiness and life satisfaction (e.g., see review Ryan \& Deci, 2016), as well as our meaning in life (Martela et al., 2018). In line with this, people with lifepartners consistently report higher levels of happiness and satisfaction with life than do single individuals (Diener et al. 1999; Dolan \& Peasgood 2008; Gustavson et al., 2015; Haring-Hidore et al. 1985; Naess et al., 2015; Veenhoven 1994). In their review of the literature, Waite and Gallagher (2000) noted that life-partners also provide a sense of meaning or purpose for the other person, that partners make life seem more worthwhile. Moreover, longitudinal studies demonstrate that being in a relationship is a strong negative predictor of depressive symptoms (e.g., Horwitz et al., 1996; Kim \& McKenry, 2002). Such evidence regarding autonomy and relatedness is widely accepted as being paramount when examining factors of influence to wellbeing. Given the fundamental importance that satisfaction of these basic needs plays in contributing to our wellbeing, we also examined how nature-related factors impact wellbeing when considered simultaneously with respondents' sense of control over their lives and their relationship status.

\section{Method}

\subsection{YouGov/National Trust survey overview}

YouGov is an international public-opinion and research-data group based in London, United Kingdom, that conducts objective, demographically-representative surveys. The National Trust is a large non-profit organization dedicated to preserving the integrity of the UK's heritage sites and natural places. In 2019, The National Trust commissioned YouGov to conduct a stratifiedsample survey across the United Kingdom examining adults' relationship with nature. Aimed at capturing a comprehensive picture, the survey included items pertaining to nature experiences and nature-related activities engaged in, attitudes towards and feelings about nature, along with aspects of individuals' emotional/psychological wellbeing and physical health.

\subsection{Participants}

The sample consisted of 2,096 respondents. Biological sex was nearly evenly split between males $(47.2 \%)$ and females (52.8\%); ages ranged from 16 to $55+$, with $51 \%$ of respondents between the ages of 25 and 54 years, and $41 \%$ of respondents over the age of 55 years (8\% were between 16 and 24 years). Over half (61\%) of our sample came from a higher (vs. lower) socio-economic 
grade. ${ }^{1}$ Fieldwork was undertaken between $29^{\text {th }}$ to $30^{\text {th }}$ July 2019 . The survey was carried out online. The data have been weighted and representative of all UK adults 16+ years of age.

\subsection{Measures of dependent variables: Wellbeing, illbeing, general physical health}

The YouGov/National Trust survey assessed emotional wellbeing, emotional illbeing, and general physical health with several items. We selected the items routinely used to produce national statistics through population surveys, for example by the ONS $(2012,2018)$ in the UK, to monitor population wellbeing. These items also closely align with items commonly found in measures utilized by wellbeing researchers in the field of positive psychology. Thus in the current study, hedonic wellbeing was assessed with the item "In general, do you feel happy?", while eudaimonic wellbeing was assessed with the item "To what extent do you feel that the things you do in your life are worthwhile?". Respondents rated both of these items on a scale ranging from $0=$ not at all happy/worthwhile to $10=$ very happy/completely worthwhile (respectively). Single item measures of mental and physical wellbeing have been found acceptable, especially when used with large samples (e.g., Cunny \& Perri, 1996; Hyland \& Sodergren, 1996). Additionally, these items (or very similar) have been used successfully in similar contexts and have been found to correlate highly with respective multi-item scales of happiness and meaning in life (Abdel-Khalek, 2006; Cheung \& Lucas, 2014; Oishi \& Diener, 2013; Richardson et al., 2016; Richardson \& McEwan, 2018; Steger \& Kashdan 2013).

The YouGov/National Trust survey also presented respondents with a range of mental and physical diagnoses, to which they could choose either " $1=\mathrm{No}^{\prime}$ " or " $2=$ Yes" if they have ever been diagnosed with the ailment. (Of course, respondents could also choose to not answer at all or choose a "Prefer not to say" option.) Of these items, we summed the "yes/no" responses to 'anxiety' and 'depression' to assess emotional illbeing in the current study. Lastly, to broadly assess general physical health, we used the survey item "In general, would you say your health is ___ with responses on a 5-point scale ranging from $1=$ Poor to 5 = Excellent. Similar one-item measures of general physical health have been shown to be reliable, with results being in line with objective measures of physical health (e.g., Macias et al., 2015; Meng et al., 2014).

\subsection{Measures of predictor variables}

As noted in the introduction, we examined seven factors as predictors of wellbeing: nature connectedness, time in nature, engagement with nature through simple activities, indirect engagement with nature, knowledge and study of nature, autonomy, and relationship status. (See Table 1 below for summary list of all items with response scales comprising these factors; items are also described below.)

\subsubsection{Factor 1: Nature connectedness}

The Inclusion of Nature in Self Scale (INS; Schultz, 2001) was selected from the survey items to measure nature connectedness. The INS is widely-used as an assessment of nature connectedness. The INS comprises a single item which asks the respondent to select one of seven diagrams that best describes their relationship with the natural environment. Diagrams depict

\footnotetext{
${ }^{1}$ Socio-Economic Grade was defined using 2 levels: ABC1 = high/intermediate managerial, administrative, or professional; supervisory, clerical, and junior managerial, administrative, or professional; C2DE = skilled manual worker, semi and unskilled manual workers, state pensioners, casual or lower grade workers, unemployed with state benefits only.
} 
increasing degrees of overlap between a circle labelled "Self" and a circle labelled "Nature", such that higher scores (from 1 to 7 ) indicate a greater connection with nature. In the current study, $M=4.03, S D=1.72$.

Table 1. All items used in initial analyses

\begin{tabular}{cl}
\hline \multicolumn{1}{c}{ Factors and Potential Items } & \multicolumn{1}{c}{ Response Scale } \\
\hline Factor 1. Nature Connectedness (NC) & \\
\hline NC1. Inclusion of Nature in Self Scale & $\begin{array}{l}\text { choose which diagram of 7 } \\
\text { best depicts relationship with } \\
\text { nature }\end{array}$
\end{tabular}

Factor 2. Time in Nature (TiN)

TiN1. In an average week, how many days do you spend more $1={ }^{\prime}$ None' to $5={ }^{\prime}$ Every day, 7 than 1 hour in nature.

days'

Factor 3. Engagement with Nature Through Simple Activities (SA)

SA1. Sit or relax in a garden. $1=$ 'Never' to $4=$ 'Often'

SA2. Watch wildlife (e.g., bird watching etc.) $1=$ 'Never' to $4=$ 'Often'

SA3. Listen to bird song. $1=$ 'Never' to $4=$ 'Often'

SA4. Smelt wildflowers. $1=$ 'Never' to $4=$ 'Often'

SA5. Taken a photo / drawn or painted a picture of a natural $1=$ 'Never' to $4=$ 'Often' views, plant, flower or animal.

SA6. Collected shells or pebbles on the beach. $\quad 1=$ 'Never' to $4=$ 'Often'

SA7. Take time to notice butterflies and/or bees. $1=$ 'Never' to $4=$ 'Often'

Factor 4. Indirect Engagement with Nature (IND)

IND1. Watch or listen to nature programmes on the TV or radio. $1=$ 'Never' to $4=$ 'Often'

IND2. Look at books, photos, or websites about the natural world. $1=$ 'Never' to $4=$ 'Often'

IND3. Talk about nature or wildlife with family or friends (online $1=$ 'Never' to $4=$ 'Often' or face-to-face).

Factor 5. Knowledge and Study of Nature (KS)

KS1. I know a lot about nature and wildlife (such as birds, animals, $1=$ 'Strongly disagree' to $5=$ insects, etc.)

KS2. Studied nature with a microscope or binoculars.

'Strongly agree'

$1=$ 'Never' to $4=$ 'Often'

Factor 6. Autonomy (Auto)

S-D1. There's little I can do to change my life.

$1=$ 'Strongly agree' to $7=$

'Strongly disagree'

Factor 7. Relationship Status (R-S)

RS1. Life partner status

$1={ }^{\prime} \mathrm{Yes}^{\prime}, 2={ }^{\prime} \mathrm{No}^{\prime}$

\subsubsection{Factor 2: Time spent in nature}

This factor consisted of one item: "In an average week, how many days do you spend more than 1 hour in nature". Response scale ranged from $1=$ None to $5=$ Every day, 7 days such that higher scores indicate more time spent in nature. In the current study, $M=3.03, S D=1.25$. 


\subsubsection{Factor 3: Engagement with nature through simple activities}

Seven items describing a selection of common, simple nature-related experiences that people might have engaged in over the past year were included in this factor. These items were informed by the Biophilic Values (Kellert, 1993) and the nature connectedness pathways (Lumber et al., 2017). Some activities were more passive (i.e., 'sit or relax in a garden', 'watch wildlife [e.g. bird watching etc.]'), while others were more active (i.e., 'collected shells or pebbles on the beach', 'taken a photo of or drawn/painted a picture of a natural view, plant, flower, or animal'). Activities involving different senses and different aspects of nature were included (i.e., 'listen to bird song', 'smelt wildflowers', 'take time to notice butterflies and/or bees'). All items constituted some degree of direct exposure to and engagement with live nature. Response scales ranged from $1=$ Never to $4=$ Often. Descriptives for each activity are as follows: Sit or relax in a garden: $M=3.06, S D=0.90$; Watch wildlife: $M=2.51, S D=1.06$; Listen to bird song: $M=3.00, S D=1.00$; Smell wildflowers: $M=2.62, S D=0.99$; Draw or take photo of nature: $M=2.33, S D=1.11$; Collected shells or pebbles on beach: $M=2.10, S D=0.96$; Take time to notice butterflies/bees: $M$ $=3.05, S D=0.94$.

\subsubsection{Factor 4: Indirect engagement with nature}

Three items (inspired by Soga et al., 2016) captured current frequency of indirect engagement with nature (i.e., 'watch or listen to nature programmes on the TV or radio, 'look at books, photos, or websites about the natural world, 'talk about nature or wildlife with family or friends [online or face-to-face]'). The response scale was the same as for simple activities; that is from $1=$ Never to $4=$ Often. Descriptives for these items are as follows: Watch/listen nature programmes: $M=$ 2.77, $S D=0.92$; Look at books/photos of nature: $M=2.53, S D=0.92$; Talk about nature with family/friends: $M=2.73, S D=0.92$.

\subsubsection{Factor 5: Knowledge and study of nature}

Two items were included in this factor, one assessing knowledge (i.e., 'I know a lot about nature and wildlife [such as birds, animals, insects, etc.'; response scale from $1=$ Strongly disagree to $5=$ Strongly agree) and one assessing a behavioural aspect of studying nature ('Studied nature with a microscope or binoculars.'; response scale $1=$ Never to $4=$ Often). Descriptives for these items are as follows: Knowledge: $M=3.13, S D=1.03$; Study: $M=1.65, S D=0.90$.

\subsubsection{Factor 6: Autonomy}

One item was included to assess autonomy: 'There's little I can do to change my life', which was rated on a 7-point scale from $1=$ Strongly agree to $7=$ Strongly disagree. This item was recoded before analysis such that higher scores indicated greater control over one's life. Descriptives for this item are: $M=4.76, S D=1.66$.

\subsubsection{Factor 7: Relationship status}

This item asked respondents to indicate their married/civil partnership status. Response choices were: 'married/civil partnership', 'living as married', 'separated/divorced', 'widowed', or 'never married'. For simplicity in the current study, to assess if respondents had a life partner, we recoded these responses as follows: 1 = Yes; combining 'married/civil partnership' with 'living as married'; and 2 =No; combining 'separated/divorced', 'widowed', and 'never married'. In this 
sample using this metric, $59.8 \%$ of respondents fell into the category of having a life partner, while the remaining $40.2 \%$ fell into the category of not having a life partner.

\section{Results}

Sample size provided adequate power for the number of variables entered (sample size estimated for small effect size, $\alpha=.05$, power $=.80 ; 7$ predictors: suggested $N=725$ ). Multiple linear regression assumptions for multicollinearity, independent errors, and normality of residuals were met for all regressions (Durbin-Watson $=1.94-2.11$, VIF: 1.03 - 2.03; Tolerance: $0.48-0.97$, highest $r s=.078-.321)$. However, the homoskedasticity assumption was violated for some of the multiple regressions (i.e., Breusch-Pagan and Koenker $p s<.050$ ). When the homoskedasticity assumption is violated, significance tests and confidence intervals can be both biased and inconsistent, although relative beta values remain unaffected. If the heteroskedasticity assumption is violated, Hayes and Cai, 2007 recommend (as do Long and Ervin, 2000) that heteroskedasticity-consistent (HC) standard error estimators for OLS regression and resulting significance values be employed. In this approach, the regression model is estimated using OLS, but standard errors (and thus significance values) are estimated by a method which does not assume homoskedasticity. In line with these recommendations and for consistency, we employed Hayes' (2017) RLM v1.01 and Daryanto's (2018) heteroskedasticity macros for SPPS and used HC3 methods to estimate the significance of predictor values in all regressions. Indeed, Hayes and Cai recommend using the HC3 estimator method as the default method for all multiple regressions (p. 716).

\subsection{Correlations between predictor items and wellbeing aspects}

Bivariate correlations were examined between each of the original 16 predictor items and the four wellbeing dependent variables. As shown in Table 2 below, significant correlations emerged between each of the 16 predictor items and our wellbeing dependent variables of happiness and life feeling worthwhile. With regard to bivariate correlations with illbeing, only two of the seven "engagement with nature through simple activities" (SA) items emerged as significant correlates, only one of the "indirect direct engagement with nature" (IND) items and one of the "knowledge and study of nature" (KS) items emerged as significant correlates. For bivariate correlations with general physical health, five of the seven SA items, two of the IND items, and one of the KS items emerged as significant correlates. The autonomy item and the relationship-status item were significantly correlated with all four aspects of wellbeing.

\subsection{Linear regressions to determine significant predictor items for each wellbeing aspect}

We regressed each wellbeing aspect (i.e., happy, worthwhile life, illbeing, general physical health) separately onto (1) items from engagement with nature through simple activities (SA), (2) items from indirect engagement with nature (IND), and (3) items from knowledge and study of nature (KS). Thus, three regressions were run for each wellbeing aspect. (See Table 3 below for a summary of significant items; see Supplemental Tables 1 to 4 for complete statistics.) In both the prediction of happiness and the prediction of feeling that life is worthwhile, two SA items (SA1 - sit or relax in a garden, and SA4 - smelt wildflowers), one IND item (IND1: watch or listen to nature programmes on the TV or radio), and one KS item (KS2 - studied nature with a microscope or binoculars) emerged as significant in the respective regressions. In both the prediction of illbeing and the prediction of general physical health, the SA1 item (sit or relax in a garden) and the KS2 item (study nature) emerged as significant in the respective regressions. The IND1 item (nature programmes) emerged as significant for the prediction of illbeing, while 
the IND3 item (talking about nature with friends of family) emerged as significant for the prediction of general physical health. We computed a composite measure for the SA Factor for happiness and life worthwhile utilizing the SA1 and SA4 items that had emerged as significant for use in subsequent analyses.

Table 2. Correlations: Individual predictor variable with dependent variables

\begin{tabular}{|c|c|c|c|c|c|c|c|c|c|c|c|c|c|c|}
\hline & $\mathrm{NC}$ & Time & SA1 & SA2 & SA3 & SA4 & SA5 & SA6 & SA7 & IND1 & IND2 IND3 & KS1 & KS2 & Auton. Partner \\
\hline Happy & $.270^{* *}$ & $.240^{* *}$ & $.267^{* *}$ & $.110^{* *}$ & $.132^{* *}$ & $.228^{* *}$ & $.088^{* *}$ & $.164^{* *}$ & $.166^{* *}$ & $.149^{* *}$ & $.097^{* *} .093^{* *}$ & $.058^{* *}$ & $151^{* *}$ & $.302^{* *}-.217^{* *}$ \\
\hline
\end{tabular}

Worth- $.327^{* *} \cdot 260^{* *} \cdot 281^{* *} \cdot 141^{* *} \cdot 165^{* *} 257^{* *} \cdot 102^{* *} \cdot 166^{* *} \cdot 192^{* *} \cdot 164^{* *} \cdot 126^{* *} \cdot 114^{* *} \cdot 093^{* *} \cdot 188^{* *} \cdot 317^{* *}-.207^{* *}$ while

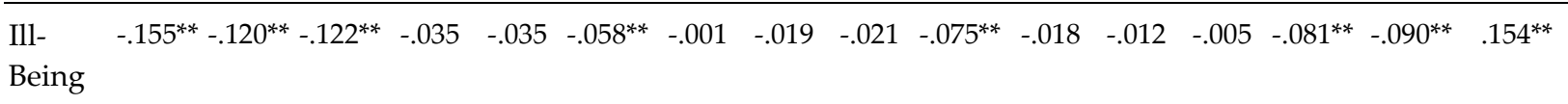

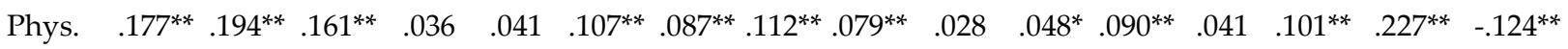
Health

Note. ${ }^{*} p<05,{ }^{* *} p<.01 ; \mathrm{NC}=$ nature connectedness; Time = time in nature; SA = simple activity, SA1: sit/relax garden, SA2: watch wildlife, SA3:listen birdsong, SA4: smelt wildflowers, SA5: taken photo/drawn photo of nature, SA6: collect shells/pebbles on beach; SA7: notice butterflies \&/or bees; IND = indirect engagement with nature, IND1: watch/listen nature programmes, IND2: look at books/photos/websites of nature, IND3: talk about nature with friends/family; KS = knowledge \& study of nature, KS1: know a lot about nature, KS2: study nature w/binoculars or microscope; Auton. = autonomy/control over one's life; Partner =1 = yes, 2 = no having a life partner; Phys. Health = general physical health

\subsection{Linear regressions to determine significant predictor factors for each wellbeing aspect}

Next we examined the relative predictive significance of the seven factors (i.e., nature connectedness, time in nature, engagement with nature through simple activities, indirect engagement with nature, knowledge and study of nature, autonomy, and relationship status) on each wellbeing aspect. To do so, we regressed each wellbeing aspect (separately) onto the seven factors using only the (respective) significant individual items and composite item from previous steps reported above. (See Table 3 for summary of items comprising the factors for each regression.)

As detailed in Table 4 below, autonomy and relationship status emerged as significant predictors of all four wellbeing aspects (i.e., happiness, feeling that life is worthwhile, illbeing, and general physical health). Nature connectedness and simple activities emerged as significant predictors of happiness, feeling that life is worthwhile, and illbeing ( $p$ s $<.001$ except for simple activities predicting illbeing where $p=.047)$. Time in nature, indirect engagement with nature, and knowledge/study of nature did not emerge as significant predictors of happiness, feeling that life is worthwhile, and illbeing $(.107<p<.941)$. In the prediction of general physical health, both nature connectedness and time in nature emerged as significant predictors (respective $p \mathrm{~s}<.004, .001$ ), while simple activities, indirect engagement with nature, and knowledge/study of nature did not emerge as significant (respective $p \mathrm{~s}=.102, .254, .628$ ). 
Table 3. Significant SA, IND, and KS items which emerged in regressions predicting wellbeing

\begin{tabular}{lcccc}
\hline $\begin{array}{l}\text { Items that emerged as } \\
\text { significant in } \\
\text { respective linear } \\
\text { regressions }\end{array}$ & Happiness & Life Worthwhile & Illbeing & $\begin{array}{c}\text { General Physical } \\
\text { Health }\end{array}$ \\
\hline $\begin{array}{l}\text { Factor 3. Simple } \\
\text { Activities }\end{array}$ & $\begin{array}{c}\text { SA1: sit or relax in } \\
\text { garden } \\
\text { SA4: smelt } \\
\text { wildflowers }\end{array}$ & $\begin{array}{c}\text { SA1: sit or relax in } \\
\text { garden } \\
\text { SAl: smelt } \\
\text { wildflowers }\end{array}$ & $\begin{array}{c}\text { SA1: sit or relax in } \\
\text { garden }\end{array}$ & $\begin{array}{c}\text { SA1: sit or relax in } \\
\text { garden }\end{array}$ \\
\hline $\begin{array}{l}\text { Factor 4. Indirect } \\
\text { Engagement }\end{array}$ & $\begin{array}{c}\text { IND1: nature } \\
\text { programmes }\end{array}$ & $\begin{array}{c}\text { IND1: nature } \\
\text { programmes }\end{array}$ & $\begin{array}{c}\text { IND1: nature } \\
\text { programmes }\end{array}$ & $\begin{array}{c}\text { IND3: talk about } \\
\text { nature }\end{array}$ \\
\hline $\begin{array}{l}\text { Factor 5. Knowledge } \\
\text { \& Study }\end{array}$ & $\begin{array}{c}\text { KS2: study nature } \\
\text { w/binocs }\end{array}$ & $\begin{array}{c}\text { KS2: study nature } \\
\text { w/binocs }\end{array}$ & $\begin{array}{c}\text { KS2: study nature } \\
\text { w/binocs }\end{array}$ & $\begin{array}{c}\text { KS2: study nature } \\
\text { w/binocs }\end{array}$ \\
\hline
\end{tabular}

See Supplemental Tables 1 to 4 for complete regression statistics with standardized beta value and HC3 $p$ estimates

\begin{tabular}{|c|c|c|c|c|}
\hline $\begin{array}{l}\text { Summary of items for } \\
\text { factor linear } \\
\text { regressions }\end{array}$ & Happiness & Life Worthwhile & Illbeing & $\begin{array}{c}\text { General Physical } \\
\text { Health }\end{array}$ \\
\hline $\begin{array}{l}\text { Factor 1: Nature } \\
\text { Connectedness }\end{array}$ & $\mathrm{NC} 1$ & $\mathrm{NC1}$ & $\mathrm{NC1}$ & $\mathrm{NC1}$ \\
\hline $\begin{array}{l}\text { Factor 2: Time in } \\
\text { Nature }\end{array}$ & TiN1 & TiN1 & TiN1 & TiN1 \\
\hline $\begin{array}{l}\text { Factor 3: Simple } \\
\text { Activities }\end{array}$ & $\begin{array}{c}\text { composite of SA1 } \\
\text { and SA4 }\end{array}$ & $\begin{array}{c}\text { composite of SA1 } \\
\text { and SA4 }\end{array}$ & SA1 & SA1 \\
\hline $\begin{array}{l}\text { Factor 4: Indirect } \\
\text { Engagement }\end{array}$ & IND1 & IND1 & IND1 & IND3 \\
\hline $\begin{array}{l}\text { Factor 5: Knowledge/ } \\
\text { Study }\end{array}$ & KS2 & KS2 & KS2 & KS2 \\
\hline Factor 6: Autonomy & S-D1 & S-D1 & S-D1 & S-D1 \\
\hline $\begin{array}{l}\text { Factor 7: Relationship } \\
\text { Status }\end{array}$ & R-S1 & R-S1 & R-S1 & R-S1 \\
\hline
\end{tabular}

See Table 1 for complete description of each item.

\subsection{Dominance analyses}

Several authors have discussed the limitations of relying on simple bivariate correlations or standardized linear regression coefficients as measures of predictive or relative importance, and have argued for using a variety of techniques to augment correlational and regression analyses (Darlington \& Hayes, 2017; Johnson, 2000; Kraha et al., 2011; LeBreton et al., 2004; Tonidandel \& LeBreton, 2011). Following these best-practice recommendations, we conducted dominance and commonality analyses (reported below) to more comprehensively examine our data with respect to our nature-related predictors (Factors 1 through 5), as these were the main foci of our analyses. With the dominance analysis, we wished to examine patterns of importance, thus we followed 
Tonidandel and LeBreton's (2011) recommendation. Dominance analysis is one type of relative importance analysis; it "assesses regressor $j$ 's contribution to model fit in competition with another regressor $i$ when that competing regressor is not in the model. ... [That is], dominance analysis uses the increase in fit due to regressor $j$ relative to regressor $i$ in a model that otherwise includes only the other $k-2$ regressors. Furthermore regressors $i$ and $j$ compete against each other in all possible subset models that contain some or all of those $k$ - 2 regressors" (Darlington \& Hayes, 2017, p. 234, original emphasis). Budescu (1993) referred to a "qualitative" dominance analysis wherein predictors are ranked from 0 to 1 based on the proportion of the subset model in which adding variable $j$ increases $R$ more than does adding variable $i$. We utilized Hayes' (2017) RLM v1.01 macro for SPSS which produces a dominance matrix of these rankings.

Table 4. Linear regressions predicting happiness, life worthwhile, illbeing, and general physical health using factors

\begin{tabular}{cccccccc}
\hline DV & $\begin{array}{c}\text { Nature } \\
\text { Connectedness }\end{array}$ & $\begin{array}{c}\text { Time in } \\
\text { Nature }\end{array}$ & $\begin{array}{c}\text { Simple } \\
\text { Activities }\end{array}$ & $\begin{array}{c}\text { Indirect } \\
\text { Nature }\end{array}$ & Knowledge & $\begin{array}{c}\text { Autonomy } \\
\text { Relationship } \\
\text { Status }\end{array}$ \\
\hline Happiness & $\beta=.127$, & $\beta=.046$ & $\beta=.143$ & $\beta=.002$ & $\beta=-.002$ & $\beta=.236$ & $\beta=-.165$ \\
& $p<.001$ & $p=.108$ & $p<.001$ & $p=.940$ & $p=.944$ & $p<.001$ & $p<.001$ \\
\hline
\end{tabular}

$$
F(7,1808)=57.40, \mathrm{R}=.44, \mathrm{R}^{2}=.19, \mathrm{Adj} . \mathrm{R}^{2}=.19, p<.001
$$

Durbin-Watson $=2.05$; average VIF $=1.35$; range VIF: 1.03-1.75; average Tolerance $=0.77$; range Tolerance: $0.57-0.97$; highest-zero-order correlation: $r=.29$; Breusch-Pagan $=92.86, p<.001$; Koenker $=71.83, p<.001$

\begin{tabular}{llllllll}
\hline Life Worthwhile & $\beta=.179$ & $\beta=.036$ & $\beta=.137$ & $\beta=-.008$ & $\beta=.024$ & $\beta=.236$ & $\beta=-.158$ \\
& $p<.001$ & $p=.184$ & $p<.001$ & $p=.760$ & $p=.281$ & $p<.001$ & $p<.001$ \\
\hline
\end{tabular}

$$
F(7,1799)=63.61, \mathrm{R}=.47, \mathrm{R}^{2}=.20, \mathrm{Adj} . \mathrm{R}^{2}=.21, p<.001
$$

Durbin-Watson $=2.11$; average VIF $=1.36$; range VIF: 1.03-1.76; average Tolerance $=0.77$; range Tolerance: $0.57-0.97$;

\begin{tabular}{|c|c|c|c|c|c|c|c|}
\hline Illbeing & $\begin{array}{c}B=-.107 \\
p<.001\end{array}$ & $\begin{aligned} B & =-.016 \\
p & =.571\end{aligned}$ & $\begin{aligned} B & =-.056 \\
p & =.047\end{aligned}$ & $\begin{aligned} B & =-.008 \\
p & =.777\end{aligned}$ & $\begin{array}{c}\beta=-.015 \\
p=.540\end{array}$ & $\begin{aligned} \AA & =-.055 \\
p & =.022\end{aligned}$ & $\begin{array}{l}B=.136 \\
p<.001\end{array}$ \\
\hline
\end{tabular}
highest-zero-order correlation: $r=.32$; Breusch-Pagan $=90.62, p<.001$; Koenker $=67.26, p<.001$

$$
F(7,1785)=13.36, \mathrm{R}=.24, \mathrm{R}^{2}=.06, \mathrm{Adj} . \mathrm{R}^{2}=.05, p<.001
$$

Durbin-Watson $=2.01$; average VIF $=1.29$; range VIF: $1.03-1.62$; average Tolerance $=0.79$; range Tolerance: $0.62-0.97$; highest-zero-order correlation: $r=.17$; Breusch-Pagan $=132.12, p<.001 ;$ Koenker $=77.21, p<.001$

\begin{tabular}{cccccccc}
\hline General & $\beta=.084$ & $\beta=.096$ & $\beta=.044$ & $\beta=-.031$ & $\beta=.013$ & $\beta=.188$ & $\beta=-.094$ \\
Physical Health & $p=.004$ & $p=.001$ & $p=.102$ & $p=.254$ & $p=.628$ & $p<.001$ & $p<.001$ \\
\hline
\end{tabular}

$$
F(7,1820)=24.85, \mathrm{R}=.30, \mathrm{R}^{2}=.09, \mathrm{Adj} . \mathrm{R}^{2}=.09, p<.001
$$

Durbin-Watson $=1.95$; average VIF $=1.32 ;$ range VIF: 1.04-1.63; average Tolerance $=0.78$; range Tolerance: $0.62-0.97$; highest-zero-order correlation: $r=.22$; Breusch-Pagan $=12.35, p=.090$; Koenker $=14.66, p=.041$

Note. $\beta$ are standardized. $p \mathrm{~s}=\mathrm{HC} 3$ estimates.

In each dominance matrix produced by Hayes' RLM macro, complete dominance is denoted by a 1, indicating that in all subset models, the variable in the row completely dominates the variable in the column with respect to model fit. Partial dominance is denoted by a number greater than .50 but less than 1.00, indicating that the variable in the row increases model fit more than the 
variable in the column in only some of the subset models (Darlington \& Hayes, 2017). ${ }^{2}$ Complete model dominance ( $a$ " in all columns) indicates that adding variable $j$ increases predictive variance $(R)$ more than does adding any other variable in the model. (See Table 5 for complete dominance matrix statistics for each wellbeing dependent variable).

Table 5. Dominance analyses - composite measures predicting happiness, worthwhile, illbeing, and general physical health

\begin{tabular}{|c|c|c|c|c|c|c|c|c|c|c|c|}
\hline \multicolumn{6}{|c|}{ Happiness } & \multicolumn{6}{|c|}{ Worthwhile Life } \\
\hline & $\mathrm{NC}$ & Time & SA & Indirect & Know & & $\mathrm{NC}$ & Time & SA & Indirect & Know \\
\hline $\begin{array}{l}\text { Nature } \\
\text { Connectedness }\end{array}$ & - & 1.00 & .00 & 1.00 & 1.00 & $\begin{array}{l}\text { Nature } \\
\text { Connectedness }\end{array}$ &.- & 1.00 & 1.00 & 1.00 & 100 \\
\hline Time in Nature & .00 &.- & .00 & 1.00 & 1.00 & Time in Nature & .00 & - & .00 & 1.00 & 1.00 \\
\hline Simple Activities & 1.00 & 1.00 & - & 1.00 & 1.00 & Simple Activities & .00 & 1.00 & - & 1.00 & 1.00 \\
\hline $\begin{array}{l}\text { Indirect Nature } \\
\text { Contact }\end{array}$ & .00 & .00 & .00 & - & .75 & $\begin{array}{l}\text { Indirect Nature } \\
\text { Contact }\end{array}$ & .00 & .00 & .00 & - & .00 \\
\hline $\begin{array}{l}\text { Knowledge of } \\
\text { Nature }\end{array}$ & .00 & .00 & .00 & .25 & - & $\begin{array}{l}\text { Knowledge of } \\
\text { Nature }\end{array}$ & .00 & .00 & .00 & 1.00 & - \\
\hline \multicolumn{6}{|c|}{$\begin{array}{l}\text { Rank Order: } 1 . \text { Simple Activities, } 2 \text {. Nature } \\
\text { Connectedness, } 3 \text {. Time in Nature, } 4 \text {. Indirect Nature } \\
\text { Contact, } 5 . \text { Knowledge and Study of Nature }\end{array}$} & \multicolumn{6}{|c|}{$\begin{array}{l}\text { Rank Order: } 1 \text {. Nature Connectedness, } 2 \text {. Simple } \\
\text { Activities, } 3 . \text { Time in Nature, } 4 \text {. Knowledge and Study } \\
\text { of Nature, } 5 . \text { Indirect Nature Contact }\end{array}$} \\
\hline \multicolumn{6}{|c|}{ Ill-Being } & \multicolumn{6}{|c|}{ General Physical Health } \\
\hline & $\mathrm{NC}$ & Time & SA & Indirect & Know & & $\mathrm{NC}$ & Time & SA & Indirect & Know \\
\hline $\begin{array}{l}\text { Nature } \\
\text { Connectedness }\end{array}$ & - & 1.00 & 1.00 & 1.00 & 1.00 & $\begin{array}{l}\text { Nature } \\
\text { Connectedness } \\
\end{array}$ & - & .50 & 1.00 & 1.00 & 1.00 \\
\hline Time in Nature & .00 & - & .00 & 1.00 & .75 & Time in Nature & .50 & - & 1.00 & 1.00 & 1.00 \\
\hline Simple Activities & .00 & 1.00 & - & 1.00 & 1.00 & Simple Activities & .00 & .00 & - & 1.00 & 1.00 \\
\hline $\begin{array}{l}\text { Indirect Nature } \\
\text { Contact }\end{array}$ & .00 & .00 & .00 & - & .25 & $\begin{array}{l}\text { Indirect Nature } \\
\text { Contact }\end{array}$ & .00 & .00 & .00 & - & .125 \\
\hline $\begin{array}{l}\text { Knowledge of } \\
\text { Nature }\end{array}$ & .00 & .25 & .00 & .75 & - & $\begin{array}{l}\text { Knowledge of } \\
\text { Nature }\end{array}$ & .00 & .00 & .00 & .875 & - \\
\hline \multicolumn{6}{|c|}{$\begin{array}{l}\text { Rank Order: 1. Nature Connectedness, 2. Simple } \\
\text { Activities, 3. Time in Nature, } 4 \text {. Knowledge and Study } \\
\text { of Nature, 5. Indirect Nature Contact }\end{array}$} & \multicolumn{6}{|c|}{$\begin{array}{l}\text { Rank Order: Tied for } 1 . \text { Nature Connectedness and } \\
\text { Time in Nature, } 2 \text {. Simple Activities, } 3 \text {. Knowledge and } \\
\text { Study of Nature, } 4 \text {. Indirect Nature Contact }\end{array}$} \\
\hline
\end{tabular}

Note. $\mathrm{NC}=$ nature connectedness, Time $=$ time in nature, $\mathrm{SA}=$ engagement with nature through simple activities, Indirect $=$ indirect engagement with nature, Know $=$ knowledge and study of nature

In the prediction of happiness, engagement in simple activities in nature completely dominated all other regressors. Nature connectedness was ranked second, completely dominating the remaining three nature-related variables. Time in nature was ranked third, completely dominating indirect engagement and knowledge/study. Indirect engagement came next, partially dominating knowledge/study, which was ranked last.

In both the prediction of feeling that life is worthwhile and the prediction of illbeing, nature connectedness completely dominated all regressors. In both predictions, simple activities was

\footnotetext{
${ }^{2}$ It is important to note that this rank ordering is not necessarily the rank ordering derived from absolute values of the semipartial correlations of t-values (Darlingon \& Hayes, 2017, p. 238), thus underscoring the importance of conducting a dominance analysis.
} 
ranked second, completely dominating the remaining three nature-related variables. For a worthwhile life, time in nature was ranked third, completely dominating indirect engagement and knowledge/study. Knowledge and study of nature came next, completely dominating indirect nature engagement, which was ranked last. For illbeing, time in nature was also ranked third, completely dominating indirect engagement but only partially dominating knowledge/study. Knowledge and study of nature came next in the prediction of illbeing, partially dominating indirect engagement with nature, which was ranked last.

In the prediction of general physical health, nature connectedness and time in nature were tied for first ranking, with both variables completely dominating simple activities, indirect engagement, and knowledge/study. Simple activities was ranked second, completely dominating indirect engagement and knowledge/study. Knowledge and study of nature came next, partially dominating indirect engagement with nature, which was ranked last.

\subsection{Commonality analysis for nature connectedness, time in nature, simple activities}

Lastly, we sought to better understand the overlap between our factors of nature connectedness, time in nature, and engaging with nature through simple activities. As noted in our introduction, these three factors were of particular interest to us given that previous studies have rarely considered both time in nature and connectedness to nature in the same analysis when assessing wellbeing benefits derived from nature. Moreover, these three variables ranked as the top three variables in each dominance analysis. Thus, to assess the individual and unique contributions of these three nature factors with regard to explained variance of our four aspects of wellbeing, we conducted a series of commonality analyses (Nimon, 2010) utilizing Nimon's SPSS syntax.

Commonality analysis provides a more thorough understanding of regression analysis because it partitions the explained variance based on the unique and nonunique contributions of each variable (Nimon, 2010; Nimon et al., 2008; Ray-Mukherjee et al., 2014). Unique effects refer to the portion of variance that is unique to each particular variable. Nonunique effects (i.e., common or shared effects) identify the portion of variance that is common to or shared with every other variable in the regression. Thus, commonality analysis provides a more complete picture of the relationship between predictor variables and a dependent variable. As Siebold and McPhee (1979) noted, the usefulness of research findings "depend not only on establishing that a relationship exists among predictors and the criterion, but also upon determining the extent to which those independent variables, singly and in all combinations, share variance with the dependent variable" (p. 355) [emphasis added].

As depicted in Figures 1, 2, and 3 (below), variance shared amongst nature connectedness, time in nature, and simple activities accounted for the largest proportion of explained variance in happiness, a worthwhile life, and illbeing, 27\%-33\%. At the same time, nature connectedness uniquely accounted for $17-31 \%$, and simple activities accounted for $15 \%-20 \%$ of explained variance in these aspects of wellbeing. Time in nature uniquely accounted for only $1 \%$ of explained variance in each of the three wellbeing aspects. Variance shared between: nature connectedness and simple activities accounted for $7 \%-15 \%$; simple activities and time in nature accounted for 7\%-9\%, and time in nature and nature connectedness 5\%-12\%.

With regard to general physical health (see Figure 4 below), variance shared amongst all three variables accounted for $27 \%$ of the explained variance. Nature connectedness uniquely accounted for $15 \%$, simple activities for $12 \%$, and time in nature for $10 \%$ of explained variance. Variance shared between: nature connectedness and simple activities accounted for $5 \%$; simple activities and time in nature accounted for $15 \%$ and time in nature and nature connectedness 
$16 \%$.

Figure 1. Commonality analysis for explained variance in happiness

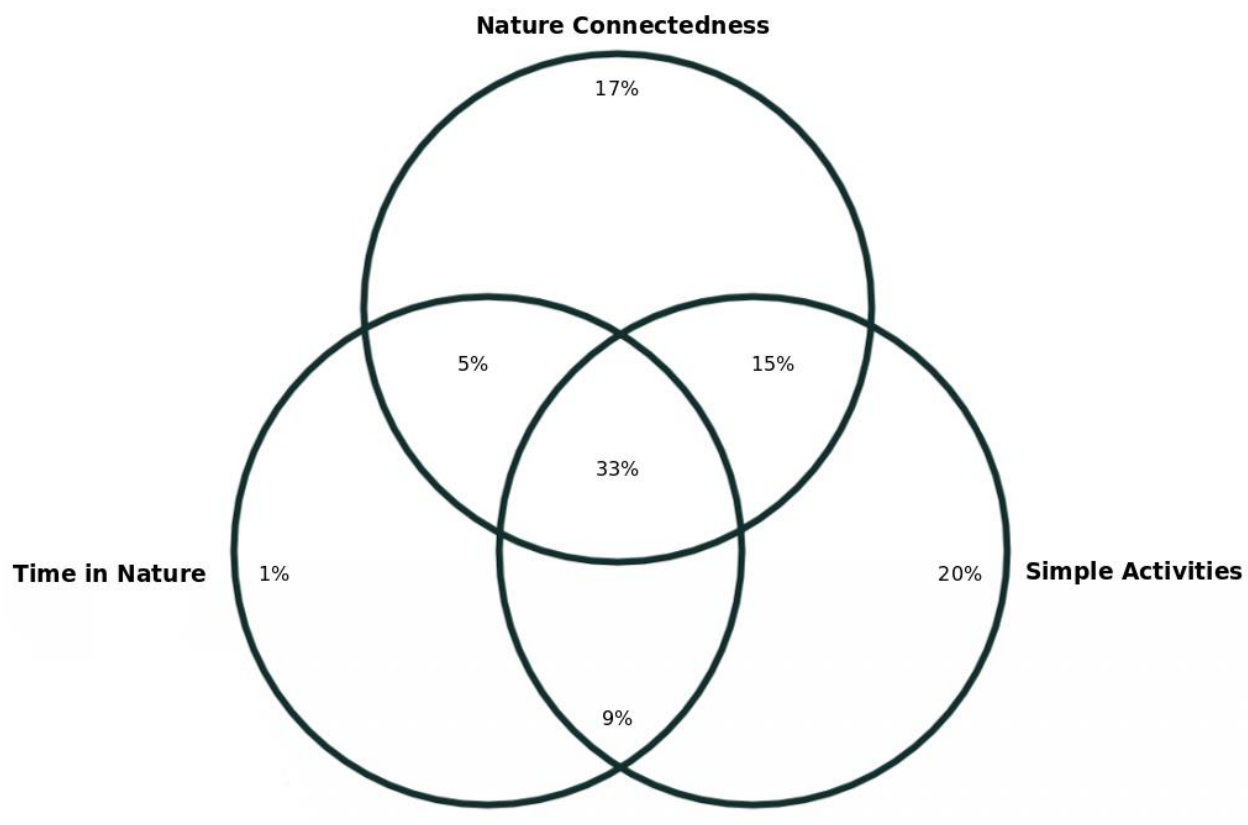

Figure 2. Commonality analysis for explained variance in feeling life is worthwhile

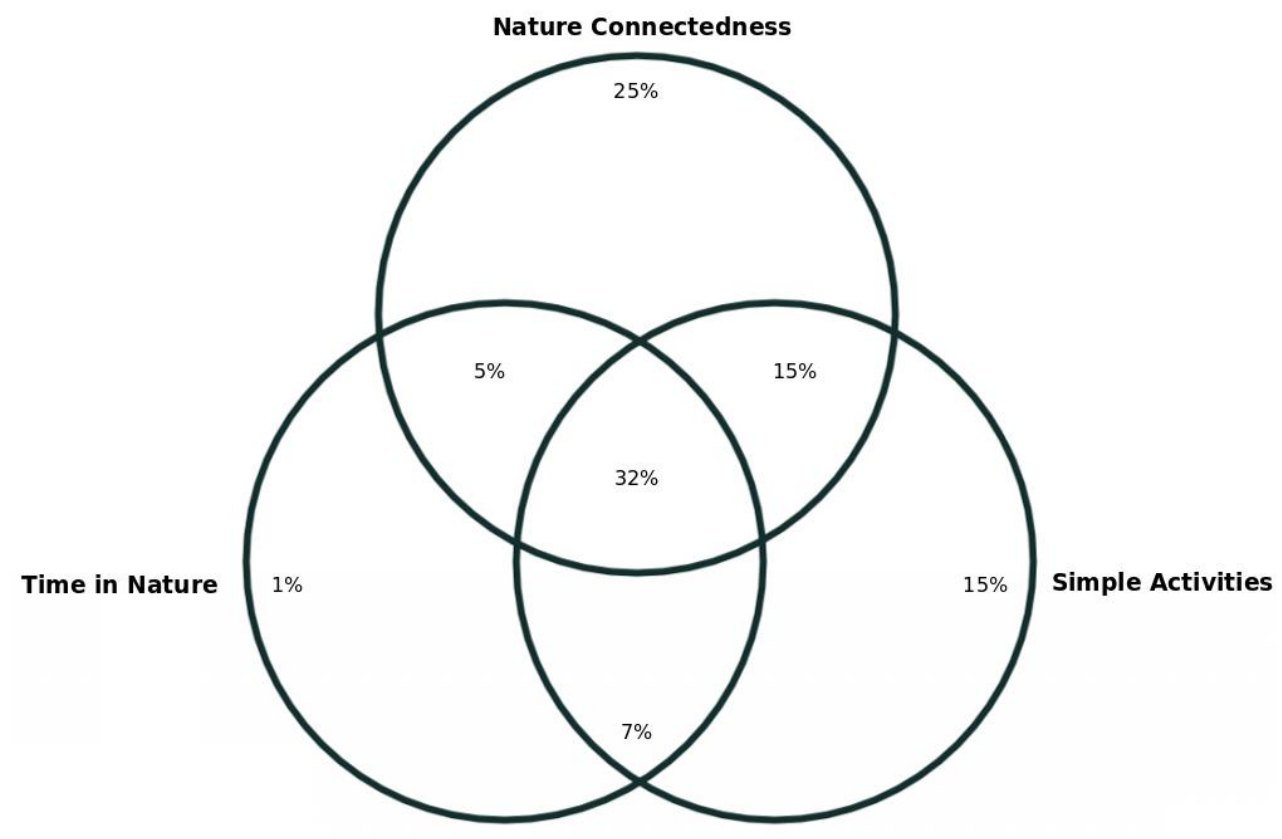


Figure 3. Commonality analysis for explained variance in ill-being (anxiety and depression)

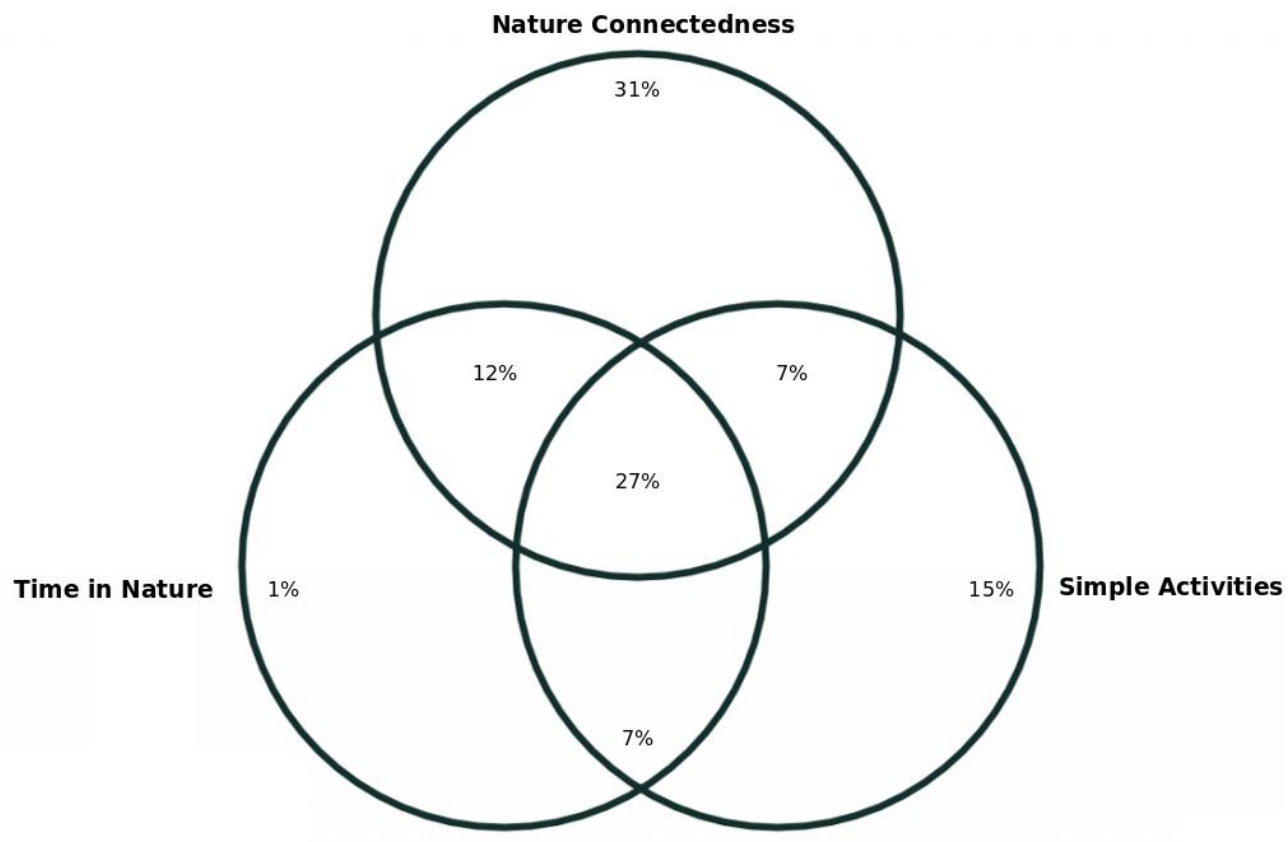

Figure 4: Commonality analysis for explained variance in general physical health

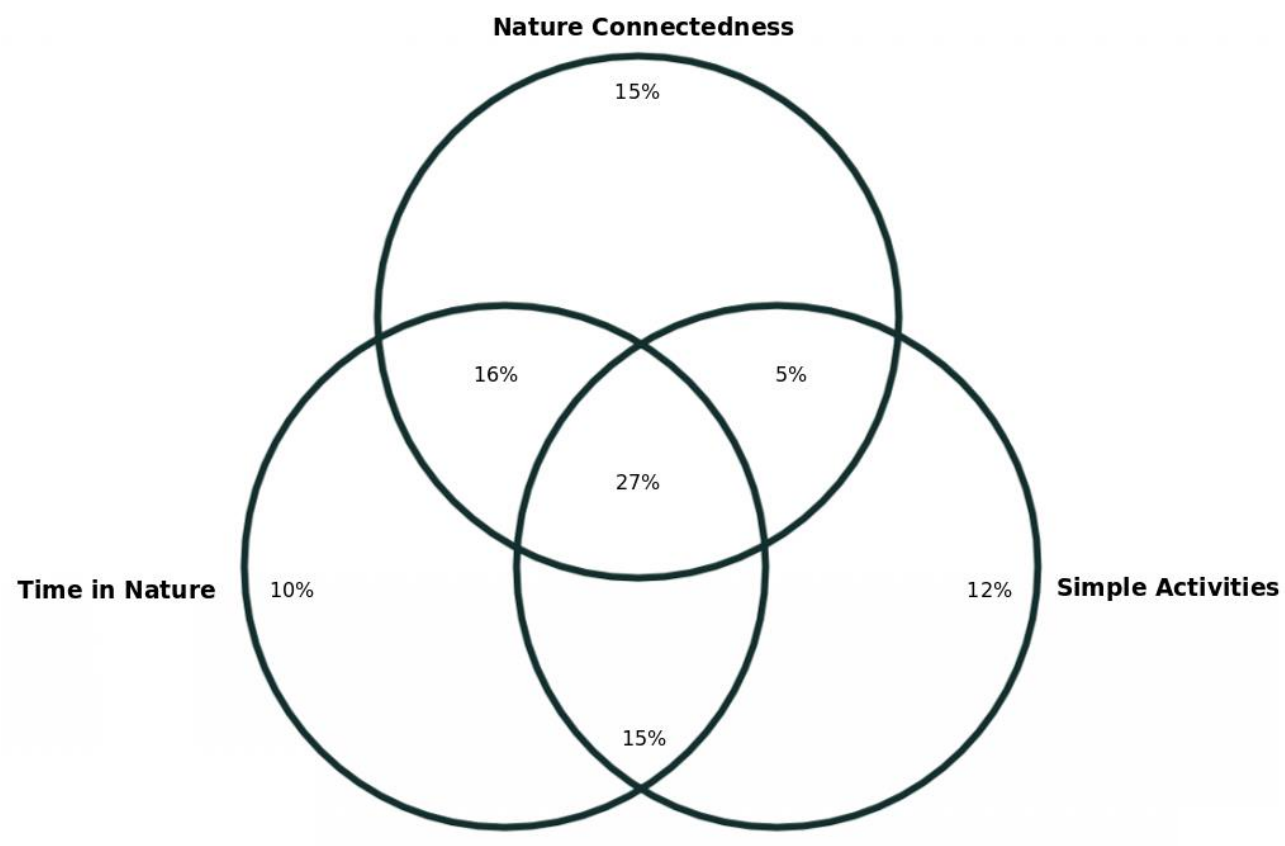

\section{Discussion}

A plenitude of research has consistently evidenced that engaging with nature is good for our mental health and wellbeing (e.g., see review Capaldi et al., 2105; McMahan \& Estes, 2015). Various aspects of engagement with nature have been studied and empirical evidence produced demonstrating nature's beneficial effect on wellbeing. This includes studies focusing on time spent in, or direct contact with, nature (e.g. Meredith et al., 2020; Richardson et al., 2016; White et al. 2019), engaging with nature through simple activities aligned with the pathways to nature connectedness (e.g., Lumber et al., 2017), indirect contact with nature (e.g., White et al., 2018), noticing nature (McEwan et al., 2019; Passmore \& Holder, 2017), and having a strong 
psychological and emotional connection with nature-nature connectedness (e.g. Capaldi et al., 2014; Pritchard et al., 2019). However little research has examined the wellbeing impact of these nature-related factors when considered in concert with each other. In the current study, our primary focus was to examine the patterns and relative predictive importance of five naturerelated factors (nature connectedness, time in nature, engagement with nature through simple activities, indirect engagement with nature, and knowledge and study of nature) to hedonic and eudaimonic wellbeing, illbeing, and general physical health.

We conducted correlational, linear regression, dominance, and commonality analyses. A significant relationship emerged between each of the four wellbeing measures (happiness, feeling that life is worthwhile, illbeing, and physical health) and the majority of the 14 naturerelated predictor items. However, when considered alongside each other, a different pattern emerged. When examining the factors that explained variance in wellbeing and illbeing using multiple linear regressions, only nature connectedness and engaging in simple nature activities emerged as significant; the association with time in nature was not significant, nor were indirect contact with nature or knowledge/study of nature. Even when we considered two basic components of a good life, satisfaction of the basic psychological needs of autonomy (i.e., a sense of control over one's life) and relatedness (via relationship status), nature connectedness and engaging with nature through simple activities still emerged as being significantly related to happiness, feeling that life is worthwhile, and lower rates of illbeing. Although there are many complex factors involved in wellbeing, these results support suggestions that nature connectedness itself - tuning into nature - is a core psychological need and basic component of a good life (Baxter \& Pelletier, 2019; Hurly \& Walker, 2019).

It should be noted that relaxing in the garden and smelling wildflowers were the only significant items in the simple activities group. While smelling wildflowers is a simple engagement activity, relaxing in the garden could include non-nature engagement activities. Although correlated to wellbeing outcomes, items such as listening to birdsong or watching wildlife did not emerge as significant individual items in the regression. Hence results, particularly for illbeing and physical health, could reflect the benefits of having a garden rather than simple engagement with nature (Brindley et al., 2018). However, the commonality analysis did reveal a large overlap between nature connectedness, time in nature, and the simple activities items, supporting the validity of this grouping.

Nature connectedness and simple engagement with nature were also evident in the results of the dominance analyses, wherein nature connectedness completely dominated all the other nature-related factors in predicting a worthwhile life and lowered illbeing, and engaging in simple nature activities was ranked as second. For happiness, engaging with nature through simple activities completely dominated all other nature-related factors, with nature connectedness being ranked second. It is important to note that "complete dominance does not typically occur in real data" (Kraha et al., 2012, p. 4). This speaks to the powerful impact that nature connectedness and engagement with nature through simple activities have on our mental health and wellbeing.

This prominence of nature connectedness and engaging in simple nature activities in accounting for the variance in mental health and wellbeing was also evident in results of the commonality analyses. Nature connectedness and engagement with nature through simple activities each uniquely accounted for far more of the explained variance in happiness $(17 \%$, $20 \%)$, a worthwhile life $(25,15 \%)$, and lower wellbeing $(31 \%, 15 \%)$, than did time in nature. Indeed, time in nature uniquely accounted for only $1 \%$ of the explained variance in each of happiness, a worthwhile life, and lower illbeing. 
Thus, results were consistent across these analytical methodologies: connectedness to nature and engaging with nature through simple activities were more closely linked to higher wellbeing and lower illbeing than were any of the other nature-related factors, including time in nature. The findings of time in nature as a lesser-factor may seem odd. After all, solid research has demonstrated that time in nature is important for wellbeing (e.g., Meredith et al., 2020; White et al., 2019). However as noted in our introduction, this research has generally overlooked individual factors of nature connection and engagement. Findings from the current study suggest that when added to the equation, these person-based factors have stronger relationships with wellbeing than does time in nature, which may have been acting as a proxy measure for connection and engagement. Being connected and engaging with nature generally involves spending time in nature, yet time in nature is not necessarily driven by a close connection with nature and may not involve active engagement with nature. Time does not tell the full story. What matters is how that time is spent-developing and being in a close relationship with nature.

Although the first to include nature connectedness and time in nature together in a largerscale survey, our results are in line with previous experimental research which also suggested that the amount of time in nature is not necessarily the essential factor to enhance mental health and wellbeing, but rather the essential factor is if one attends to the nature they are in. For instance, Passmore and Holder (2017) reported that participants who noticed how everyday nature made them feel reported significantly higher levels of wellbeing (positive affect, elevation, a general transcendent connectedness) than did control participants, despite not having spent significantly more time in nature. Nisbet and colleagues (2019) reported that in their study, participants who received mindfulness instruction before a 20-minute walk in nature reported substantially less negative affect at the end of their walk than did participants who had gone for a 20-minute in nature without first receiving mindfulness instructions. Moreover, these mindful individuals also reported significantly stronger connectedness with nature compared to those who had walked in nature without being particularly mindful of their surroundings. Similarly, McEwan and colleagues $(2019,2020)$ found that participants who noted three good things in nature while engaged in simple interactions with close-to-home nature reported not only improved mental health and wellbeing, but also enhanced nature connectedness.

With regard to general physical health, of the nature-related factors, time in nature and nature connectedness evidenced the largest bivariate correlations. In a linear regression, only time in nature and nature connectedness emerged as significant predictors of general physical health; these remained significant even when considering control over one's life and relationship status. The dominance analysis revealed a tie for first ranking between nature connectedness and time in nature. Lastly, in the commonality analysis, nature connectedness, engaging with nature through simple activities, and time in nature accounted for relatively similar percentages of explained variance in general physical health (respectively: 15\%, 12\%, 10\%). In comparison, Martin and colleagues (2020) reported that visits to nature emerged as significant while nature connectedness did not emerge as significant in a linear regression predicting general physical health. Further research examining the relative predictive importance of these factors to physical health needs to be conducted to investigate this inconsistency, albeit there is logic that time in nature would be related to factors germane to physical health such as activity levels.

\section{Limitations and future directions}

As with all studies, limitations of the current study need to be considered. Although our sample was large, our participants were based entirely in the United Kingdom; cross-cultural validation of our results utilizing samples from other countries would be helpful. Our data were 
correlational in nature, thus experimental research is needed to empirically determine causal effects, specifically directly comparing more time in nature to enhanced nature connectedness on differential impacts on wellbeing. While causal data exists which evidences that boosting nature connectedness via simple activities informed by the pathways to nature connectedness ('pathways-informed nature activities'; Lumber et al. 2017) also boosts wellbeing (McEwan et al., 2019), additional experimental studies would be informative, particularly if a broader array of wellbeing measures are used along with testing a broader array of simple pathways-informed nature activities. It would also be helpful to directly compare additional time spent in nature to the Three Good Things in Nature intervention (McEwan et al., 2019; Richardson \& Sheffield, 2017) and the Noticing Nature intervention (Passmore \& Holder, 2017) with regard to efficacy in enhancing nature connectedness and several aspects of wellbeing.

Some variable-blocks of items contained more items than others; thus it is possible that some blocks of items are more accurate than others at capturing respective nature-related dimensions and experiences. While the choice of items in each block is relatively broad, these are not exhaustive lists. It is possible that items not included in the current study would reflect additional dimensions or nuances within a variable block which could emerge as significant. Items used in the current study were taken directly from the YouGov/National Trust survey; utilizing a wider range of psychometrically validated measures of nature connectedness and of wellbeing will be important in future research. For example, additional measures of nature connectedness could be employed, such as the Nature Connection Index (Richardson et al., 2019), the Nature Connectedness Scale (Mayer \& Frantz, 2004) or the Nature Relatedness Scale (Nisbet et al., 2009). Complete measures of wellbeing could be used to more fully assess different aspects of wellbeing and illbeing; for example, standard measures could be employed such as the Scale of Positive and Negative Experiences (Diener et al., 2010), Satisfaction with Life Scale (Diener et al., 1985), Meaning in Life Questionnaire (Steger et al., 2006), Satisfaction and Frustration of Basic Needs (Chen et al., 2015), and Depression, Anxiety, and Stress Scale (Lovibond \& Lovibond, 1995). Nonetheless, items used in the current study were based on theoretical rationales and previous research (such as Martin et al., 2020), lending confidence to the emergent results reported herein.

\section{Conclusion}

These limitations notwithstanding, results of the current study reveal important insights as to significant factors associated with wellbeing. Overall, while time in nature is important for physical health (Martin et al., 2020), our findings highlight that time spent in nature is not necessarily a significant predictor of human wellbeing and mental health. Rather, simple activities and engagement which help form a close connected relationship appear to play the more substantial role.

The consistent pattern that emerged across correlational, linear regression, dominance, and commonality analyses with respect to nature-related factors and individual wellbeing provides strong support for this notion that time is not the main factor in the nature-wellbeing link. Rather, the main operant factor is connecting with nature, either through psychological or emotional connectedness or via simple engagement. By not being tuned into the nature around us, our lives are poorer for it in terms of happiness and meaning. Yet, as these findings suggest, tuning into nature-through simple acts like smelling wildflowers-help to explain differential levels of happiness ad meaning in individual's daily lives. Tuning in to nature is not about time, not about minutes. It is about moments. Feeling connected to nature and engaging in certain simple activities in nature seem to be more predictive of mental wellbeing than time spent in 
nature. Nonetheless, given the positive role of engagement with simple aspects of nature, it is important that we do not fall prey to environmental generational amnesia (Kahn, 1999), equating urban nature (no matter how varied) with the whole of nature; ensuring that people from all socio-demographic categories have the ability and means to access rural and remote nature is important.

Results of the current study, particularly when combined with the growing body of literature evidencing the importance that nature has for our wellbeing (e.g., see reviews by Bratman et al., 2019; Capaldi et al., 2014, 2015; McMahan \& Estes, 2015; Pritchard et al., 2019) are of relevance to mental health practitioners. That nature connectedness predicted greater happiness, greater levels of feeling that life is worthwhile, and lower prevalence of illbeing (i.e., depression and anxiety) beyond feeling one has control over their life and relationship status, indicates that nature connectedness measures may be a valuable tool when assessing clients' wellbeing. Pathways-informed (Lumber et al., 2017) simple nature activities could be prescribed to clients as a means of boosting mood, thereby acting as a platform from which to work on other therapeutic goals (Burns, 1998).

Results also have important practical implications for nature-based programmes and governmental policies. Perhaps foremost at a programme and policy level, would be a switch from focusing on getting people to visit natural (remote) spaces and spend more time in nature, to focusing on how people can tune in and connect with everyday nature through simple activities as this is would also help to enhance nature connectedness and thereby wellbeing (McEwan et al., 2019; Richardson \& Sheffield, 2017). Additionally, results suggest the importance of provision of garden's for rest and relaxation.

City planners could invest beyond islands of urban parks (often in affluent areas) to ensuring that nature is brought to all residents, for example, by ensuring that city streets and neighbourhoods have trees and flowers alongside (or at least visible from) walkways and routes to public transport and shopping areas. Long-term planning for urban "greenways" connecting parks, public, transit, schools, and basic-necessity shops, with prompts to notice this nature, would improve the lives of all residents. Within this, there is also need to consider how urban noise can block access to sounds of nature, such as birdsong or crickets chirping. The pathways to nature connectedness (Lumber et al., 2017) can be applied at a wider scale to inform cultural programmes and urban designs to foster and prompt engagement with nature (Richardson et al., 2020). National policies aimed at raising levels of nature connectedness, and tracking this growth, are required as an expansion to current policies which, in general, are geared towards only measuring time in or visits to nature. We join Lambert and colleagues (2020) in their call for nature connectedness to be included as a standard metric of wellbeing; we also expand this call to national and civic governmental bodies.

Nature connectedness and engaging with nature are what Knippenberg and colleagues (2018) called "genuine encounter[s] of humans and nature" which represent relational values (p. 39). We are not born tabula rasa; rather, we are born tabula relata-beings involved in relationships. Relationships are central to human life; this is why good relations are a fundamental part of eudaimonia or the 'good life'. Included in this is our relationship with the beyond-human natural world. Knippenberg and colleagues discuss "nature-inclusive eudaimonia" as a fundamental aspect of a flourishing life; Nussbaum (2011) wrote of living in harmonious relation to nature is essential to a worthwhile, meaningful life.

The rising mental health crises and rising crises in the health of our planet and its nonhuman inhabitants are indicators that our relationship with nature is broken. We need a new relationship with nature, and that starts by tuning in and noticing nature. Understanding 
that a close connection with nature is a key component of a worthwhile life, a sustainable lifea good life.

\section{Acknowledgements}

Raw data are from YouGov Plc. Total initial sample size was 2,096 adults, 16+ years of age.

\section{Informed consent}

YouGov is an international public opinion and research data group based in London, United Kingdom that conducts objective demographically-representative surveys. YouGov is a member of the British Polling Council, a corporate member of ESOMAR, and is registered with the Information Commissioner; as such, YouGov abides by all of these agency's respective rules regarding ethical consent of all survey respondents. As per these rules, all respondents provide informed consent to participate in the survey.

\section{Conflict of interest statement}

The authors report no conflicts of interest.

\section{Availability of data and material}

We intend to archive the data used in this study on the University of Derby's online research archive, UDORA, at https://derby.openrepository.com/derby/.

\section{Authors' Contributions}

Survey design was developed by Miles Richardson, Ryan Lumber, Rory Thomas, and Alex Hunt. Initial data cleaning was conducted by Holli-Anne Passmore. Review of items for inclusion in the current study was conducted by Holli-Anne Passmore and Miles Richardson. Data analysis was conducted by HolliAnne Passmore. Manuscript writing, editing, and review was conducted by Miles Richardson and HolliAnne Passmore. All authors contributed critically to the drafts and gave final approval for submission of this article.

\section{Authors}

Miles Richardson

University of Derby

M.Richardson@derby.ac.uk

Holli-Anne Passmore

University of Derby

Ryan Lumber

University of Derby

Rory Thomas

National Trust

Alex Hunt

National Trust

\section{Publishing Timeline}

Received 2 June 2020

Revised version received 2 December 2020

Accepted 21 January 2021 
Published 31 January 2021

\section{References}

Abdel-Khalek, A. M. (2006). Measuring happiness with a single-item scale. Social Behavior and Personality, 34, e1465. https://doi.org/10.2224/sbp.2006.34.2.139

Baxter, D. E., \& Pelletier, L. G. (2019). Is nature relatedness a basic human psychological need? A critical examination of the extent literature. Canadian Psychology / Psychologie canadienne, 60, 21-34. https://doi.org/10.1037/cap0000145

Beukeboom, C. J., Langevel., D., \& Tanja-Dijkstra, K. (2012). Stress-reducing effects of real and artificial nature in a hospital waiting room. The Journal of Alternative and Complementary Medicine, 18, 329-333. https://doi.org/10.1089/acm.2011.0488

Bowler, D. E., Buyung-Ali, L. M., Knight, T. M., \& Pullin, A. S. (2010). A systematic review of evidence for the added benefits to health of exposure to natural environments. BMC public health, 10(1), 456. https://doi.org/10.1186/1471-2458-10-456

Bratman, G. N., Anderson, C. B., Berman, M. G., Cochran, B., de Vries, S., Flanders , J., Folke, C., Frumkin, H., Gross, J. J., Hartig, T., Kahn, P. K. Jr., Kuo, M., Lawler, J. J., Levin, P. S., Lindahl, T., Meyer-Lindenberg, A., Mitchell, R., Ouyan, Z., Roe, J., Scarleett., ... Daily, G. C. (2019). Nature and mental health: An ecosystem service perspective. Science Advances, 5, eaax0903. https://doi.org/10.1126/sciadv.aax0903

Brindley, P., Jorgensen, A., \& Maheswaran, R. (2018). Domestic gardens and self-reported health: a national population study. International Journal of Health Geographics, 17(1), 31. https://doi.org/10.1186/s12942-018-0148-6

Budescu, D. V. (1993). Dominance analysis: A new approach to the problem of relative importance of predictors in multiple regression. Psychological Bulletin, 114, 542-551. https://doi.org/10.1037/00332909.114.3.542

Burns, G. W. (1998). Nature-guided therapy: Brief integrative strategies for health and well-being. Philadelphia, PA: Brunner/ Mazel.

Campbell, J. (1991). Reflections on the art of living: A Joseph Campbell companion. HarperCollins Publishers.

Capaldi, C. A., Dopko, R. L., \& Zelenski, J. M. (2014). The relationship between nature connectedness and happiness: A meta-analysis. Frontiers in Psychology, 5, 976. https://doi.org/10.3389/fpsyg.2014.00976

Capaldi, C. A., Passmore, H.-A., Nisbet, E. K., Zelenski, J. M. \& Dopko, R. L. (2015). Flourishing in nature: A review of the benefits of connecting with nature and its application as a wellbeing intervention. International Journal of Wellbeing, 5, 1-16. https://doi.org/10.5502/ijw.v5i4.449

Chen, B., Vansteenkiste, M., Beyers, W., Boone, L., Deci, E. L., der Kapp-Deeder, J., Duriez, B., Lens, W., Matos, L., Mouratidis, A., Ryan, R. M., Sheldon, K. M., Soenens, B., Van Petegem, S., \& Verstuyf, J. (2015). Psychological need satisfaction, need frustration, and need strength across four cultures. Motivation and Emotion, 39, 216-236. https://doi.org/10.1007/s11031-014-9450-1

Cheung, F., \& Lucas, R. E. (2014). Assessing the validity of single-item life satisfaction measures: Results from three large samples. Quality of Life Research, 23, 2809-2818. https://doi.org/10.1007/s11136-0140726-4

Costin, V., \& Vignoles, V. L. (2020). Meaning is about mattering: Evaluating coherence, purpose, and existential mattering as precursors of meaning in life judgments. Journal of Personality and Social Psychology, 4, 864-884. https://doi.org/10.1037/pspp0000225

Cunny, K. A., \& Perri, M. (1991). Single-item vs multiple-item measures of health-related quality of life. Psychological Reports, 69, 127-130. https://doi.org/10.2466/pr0.199.69.1.127

Darlinton, R. B., \& Hayes, A. F. (2017). Regression analysis and linear models: Concepts, applications, and implementation. Guilford Press.

Daryanto, A. (2018). Heteroskedasticity macro v June 19. Retrieved from https://sites.google.com/site/ahmaddaryanto/scripts/Heterogeneity-test

Diener E., Emmons, R. A., Larsen, R. J., \& Griffin, S. (1985). The Satisfaction with Life Scale. Journal of Personality Assessment, 49, 71-75. https://doi.org/10.1207/s15327752jpa4901_13 
Diener, E., Suh, E. M., Lucas, R. E., \& Smith, H. L. (1999). Subjective well-being: Three decades of progress. Psychological Bulletin, 125, 276-302. https://doi.org/10.1037/0033-2909.125.2.276

Diener, E., Wirtz, D., Tov, W., Kim-Prieto, C., Choi, D-w., Oishi, S., \& Biswas-Diener, R. (2010). New well-being measures: Short scales to assess flourishing and positive and negative feelings. Social Indicators Research, 97, 143-156. https://doi.org/10.1007/s11205-009-9493-y

Dolan, P., \& Peasgood, T. (2008). Do we really know what makes us happy? A review of the economic literature on the factors associated with subjective well-being. Journal of Economic Psychology, 29, 94122. https://doi.org/10.1016/j.joep.2007.09.001

GBD 2017 Disease and Injury Incidence and Prevalence Collaborators. (2019). Global, regional, and national incidence, prevalence, and years lived with disability for 354 diseases and injuries for 195 countries and territories, 1990-2017: A systematic analysis for the Global Burden of Disease Study 2017. The Lancet, 393, 22-28.

Gustavson, K., Røysamb, E., von Soest, T., Helland, M. J., \& Mathiesen, K. S. (2012). Longitudinal associations between relationship problems, divorce, and life satisfaction: Findings from a 15-year population-base study. The Journal of Positive Psychology, 7, 188-197. https://doi.org/10.1080/17439760.2012.61346

Haring-Hidore, M., Stock, W. A., Okun, M. A., \& Witter, R. A. (1985). Marital status and subjective wellbeing: A research synthesis. Journal of Marriage and the Family, 47, 947-953. https://doi.org/10.2307/352338

Hayes, A. F. (2017). RLM macro v. October 8. Retrieved from http://afhayes.com/regression-analysis-andlinear-models.html

Hayes, A. F., \& Cai, L. (2007). Using heteroskedasticity-consistent standard error estimators in OLS regression: An introduction and software implementation. Behavior Research Methods, 39, 709-722. https://doi.org/10.3758/BF03192961

Helzer, E. G., \& Jayawickreme, E. (2015). Control and the "good life": Primary and secondary control as distinct indicators of well-being. Social Psychological and Personality Science, 6, 653-660. https://doi.org/10.1177/1948550615576210

Horwitz, A., White, H., \& Howell-White, S. (1996). Becoming married and mental health: A longitudinal study of a cohort of young adults. Journal of Marriage and the Family, 58, 895-907. https://doi.org/10.2307/353978

Howell, A. J., \& Passmore, H.-A. (2013). The nature of happiness: Nature affiliation and mental wellbeing. In C. L. M. Keyes (Ed.), Mental well-being: International contributions to the study of positive mental health (pp. 231-257). Springer. https://doi.org/10.1007/978-94-007-5195-8_11

Hurley, J., \& Walker, G. J. (2019). Nature in our lives: Examining the need for nature relatedness as a basic psychological need. Journal of Leisure Research, 50, 290-310. https://doi.org/10.1080/00222216.2016.1578939

Hyland, M. E., \& Sodergren, S. C. (1996). Development of a new type of quality of life scale, and comparison of performance and preference for 12 global scales. Quality of Life Research, 5, 469-480. https://doi.org/10.1007/BF00540019

Inglehart, R., Foa, R., \& Peterson, C. (2008). Development, freedom and rising happiness: A global perspective (1981-2007). Perspectives on Psychological Science, 3, 264-285. https://doi.org/10.1111/j.17456924.2008.00078x

Jahoda, M. (1958). Current concepts of positive mental health. Basic Books.

Johnson, J. W. (2000). A heuristic method for estimating the relative weight of predictor variables in multiple regression. Multivariate Behavioral Research, 35, 1-19. https://doi.org/10.1207/S15327906MBR3501_1

Kahn, P. H. Jr. (1999). The human relationship with nature: Development and culture. MIT Press. https://doi.org/10.7551/mitpress/3604.001.0001

Kellert, S. H. (1993). The biological basis for human values of nature. In S. H. Kellert \& E. O. Wilson (Eds) The Biophilia Hypothesis. Washington D. C: Island Press.

Keltner, D., Bowman, R., \& Richards, H. (2017). Exploring the emotional state of 'real happiness': A study into the effects of watching natural history television content. BBC Worldwide Global Insight Team 
and University of Berkeley. Retrieved from: https://asset-

manager.bbcchannels.com/workspace/uploads/bbcw-real-happiness-white-paper-final-v258ac1df7.pdf

Kesebir, S., \& Kesebir, P. (2017). A growing disconnect from nature is evident in cultural products. Perspectives on Psychological Science, 12, 258-269. https://doi.org/10.1177/1745691616662473

Keyes, C. L. M. (2005). Mental illness and/or mental health? Investigating axioms of the complete state model of health. Journal of Consulting and Clinical Psychology, 73, 539-548. https://doi.org/10.103/0022006X.73.3.539

Kim, H. K., \& McKenry, P. C. (2002). The relationship between marriage and psychological well-being: A longitudinal analysis. Journal of Family Issues, 23, 885-911. https://doi.org/10.117/019251302237296

Kim, Y. J., \& Fusco, R. A. (2015). Does sense of control predict depression among individuals after psychiatric hospital discharge? The Journal of Nervous and Mental Disease, 203, 850-855. https://doi.org/10.1097/NMD.0000000000000380

Knippenberg, L., de Groot, W. T., van den Born, R. J. G., Knights, P., \& Muraca, B. (2018). Relational value, partnership, eudaimonia: A review. Current Opinion in Environmental Sustainability, 35, 39-45. https://doi.org/10.1016/j.cosust.2018.10.022

Kraha, A., Turner, H., Nimon, K., Reichwein Zientek, L., \& Henson, R. K. (2012). Tools to support interpreting multiple linear regression in the face of multicollinearity. Frontiers in Psychology, 3, 44. https://doi.org/10.3389/fpsyg.2012.00044

Lachman, M. E., \& Weaver, S. L. (1998). The sense of control as a moderator of social class differences in health and well-being. Journal of Personality and Social Psychology, 74, 763-773. https://doi.org/10.1037/0022-3514.74.3.763

Lambert, L, Lomas, T., van de Weijer, M. P., Passmore, H.-A., Joshanloo, M., Harter, J.., Ishikawa, Y., Lai, A., Kitagawa, T., Chen, D., Kawakami, T., Miyata, H., \& Diener, E. (2020). Towards a greater global understanding of wellbeing: A proposal for a more inclusive measure. International Journal of Wellbeing, 10. https://doi.org/10.5502/ijw.v10i2.1037

Lambert L., Passmore, H.-A., \& Holder, M. D. (2015). Foundational frameworks of positive psychology: Mapping well-being orientations. Canadian Psychology / Psychologie canadienne, 56, 311-321. https://doi.org/10.1037/cap0000033

LeBreton, J. M., Ployhart, R. E., \& Ladd, R. T. (2004). A Monte Carlo comparison of relative importance methodologies. Organizational Research Methods, 7, 258-282. https://doi.org/10.1177/1094428104266017

Long, J. S., \& Ervin, L .H. (2000). Using heteroskedasticity-consistent standard errors in the linear regression model. American Statistician, 54, 217-224. https://doi.org/10.1080/00031305.2000.10474549

Lovibond, S. H., \& Lovibond P. F. (1995) Manual for the Depression Anxiety Stress Scales. Sydney: Psychology Foundation. https://doi.org/10.1037/t39835-000

Lumber, R., Richardson, M., \& Sheffield, D. (2017). Beyond knowing nature: Contact, emotion, compassion, meaning, and beauty are pathways to nature connection. PLoS One, 12, e0177186. doi:10.1371/journal.pone.0177186

Macias, C., Gold, P. B., Ongur, D., Cohen, B. M., \& Panch, T. (2015). Are single-item global ratings useful for assessing health status? Journal of Clinical Psychology in Medical Settings, 22, 251-264. https://doi.org/10.1007/s10880-015-9436-5

Manwell, L. A., Barbic, S. P., Roberts, K., Durisko, Z., Lee, Cheolsoon, L., Ware, E., \& McKenzie, K. (2015). What is mental health? Evidence towards a new definition from a mixed methods multidisciplinary international survey. BMJ Open, 5, e00079. https://doi.org/10.1136/bmjopen-2014007079

Martela, F., Ryan, R. M., \& Steger, M. F. (2018). Meaningfulness as satisfaction of autonomy, competence, relatedness, and beneficence: Comparing the four satisfactions and positive affect as predictors of meaning in life. Journal of Happiness Studies, 19, 1261-1282. https:/doi.org/10.1007/s10902-017-9869-7

Martin, L., White, M. P., Hunt, A., Richardson, M., Pahl,S., \& Burt, J. (2020). Nature contact, nature connectedness and associations with health, well-being and pro-environmental behaviours. Journal of Environmental Psychology, 68, 101389. https://doi.org/10.1016/j.jenvp.2020.101389 
Mayer, F. S., \& Frantz, C. M. (2004). The Connectedness to Nature Scale: A measure of individuals' feeling in community with nature. Journal of Environmental Psychology, 24, 504-515. doi:/10.1016/j.jenvp.2004.10.001

McEwan, K., Ferguson, F. J., Richardson, M., \& Cameron, R. (2020). The good things in urban nature: A thematic framework for optimising urban planning for nature connectedness. Landscape and Urban Planning, 194, 103687. https://doi.org/10.1016/j.landurbplan.2019.103687

McEwan, K., Richardson, M., Sheffield, D., Ferguson, F. J., \& Brindley, P. (2019). A smartphone app for improving mental health through connecting with urban nature. International Journal of Environmental Research and Public Health, 16, 3373. https://doi.org/10.3390/ijerph16183373

McMahan, E. A., \& Estes, D. (2015). The effect of contact with natural environments on positive and negative affect: A meta-analysis. Journal of Positive Psychology, 10, 507-519. https://doi.org/10.1080/17439760.2014.994224

Meng, Q., Xie, Z., \& Zhang, T. (2014). A single-item self-rated health measure correlates with objective health status in the elderly: A survey in suburban Beijing. Frontiers in Public Health, 2, 2y. https://doi.org/10.3389.fpubh.2014.00027

Meredith, G. R., Rakow, D. A., Eldermire, E. R. B., Madsen, C. G., Shelley, S. P., \& Sachs, N. A. (2020). Minimum time dose in nature to positively impact the mental health of college-aged students, and how to measure it: A scoping review. Frontiers in Psychology. https://doi.org/10.3389/fpsyg.2019.02942

Mirowsky, J., \& Ross, C. E. (1990). Control or defense? Depression and the sense of control over good and bad outcomes. Journal of Health and Social Behavior, 31, 71-86. https://doi.org/10.2307/2137046

Naess, S., Blekesaune, M., \& Jakobsson, N. (2015). Marital transitions and life satisfaction: Evidence from longitudinal data from Norway. Acta Sociologica, 58, 63-78. https://doi.org/10.1177/0001699314563841

National Trust (2020). Noticing nature: The first report in the Everyone Needs Nature series. https://nt.global.ssl.fastly.net/documents/noticing-nature-report-feb-2020.pdf

Natural England (2020). Building partnerships for Nature's recovery. https://www.gov.uk/government/publications/natural-england-building-partnerships-for-naturesrecovery

Nimon, K. (2010). Regression commonality analysis: Demonstration of an SPSS solution. Multiple Linear Regression Viewpoints, 36, 10-17.

Nimon, K., Lewis, M., Kane, R., \& Haynes, R. M. (2008). An R package to compute commonality coefficients in the multiple regression case: An introduction to the package and a practical example. Behavior Research Methods, 40, 457-466. doi:10.3758/BRM.40.2.457

Nisbet, E. K., Zelenski, J. M., \& Grandpierre, Z. (2019). Mindfulness in nature enhances connectedness and mood. Ecopsychology, 11, 81-91. doi:10.1089/eco.20180061

Nisbet, E. K., Zelenski, J. M., \& Murphy, S. A. (2009). The Nature Relatedness Scale: Linking individuals' connection with nature to environmental concern and behavior. Environment and Behavior, 41, 715740. doi:10.1177/0013916508318748ro

Nisbet, E. K., Zelesnki, J. M., \& Murphy, S. A. (2011). Happiness is in our nature: Exploring nature relatedness as a contributor to subjective well-being. Journal of Happiness Studies, 12, 303-322. https://doi.org/10.1007/s10902-010-9197-7

Nussbaum, M. (2011). Creating capabilities: The human development approach. Harvard University Press. https://doi.org/10.4159/harvard.9780674061200

Oishi, S., \& Diener, E. (2013). Residents of poor nations have a greater sense of meaning in life than residents of wealthy nations. Psychological Science, 25, 422-430. https://doi.org/10.1177/0956797613507286

ONS. (2012). Summary of results from testing of experimental subjective well-being questions. http://www.ons.gov.uk/ons/guide-method/user-guidance/well-being/about-theprogramme/advisory-groups/well-being-technical-advisory-group/testing-of-experimentalsubjective-well-being-questions_3-december-2012.pdf

ONS (2018). Personal well-being in the UK QMI.

https://www.ons.gov.uk/peoplepopulationandcommunity/wellbeing/methodologies/personalwellbei ngintheukqmi 
Passmore, H.-A., \& Holder, M. D. (2017). Noticing nature: Individual and social benefits of a two-week intervention. The Journal of Positive Psychology, 12, 537-546. https://doi.org/10.1080/17439760.2016.1221126

Passmore, H. A., \& Howell, A. J. (2014). Nature involvement increases hedonic and eudaimonic wellbeing: A two-week experimental study. Ecopsychology, 6(3), 148-154.

Pritchard, A., Richardson, M., Sheffield, D., \& McEwan, K. (2019). The relationship between nature connectedness and eudaimonic well-being: A meta-analysis. Journal of Happiness Studies, 21, 11451167. https://doi.org/10.1007/s10902-019-00118-6

Ray-Mukherjee, J., Nimon, K., Mukherjee, S., Morris, D. W., Slotow, R., \& Hamer, M. (2014). Methods in Ecology and Evolution, 5, 320-328. doi:10.1111/2041-210X.12166

Reis, H. T., Sheldon, K. M., Gable, S. L., Roscoe, J., \& Ryan, R. M. (2000) Daily well-being: The role of autonomy, competence, and relatedness. Personality and Social Psychology Bulletin, 26, 419-435. https://doi.org/10.1177/0146167200266002

Richardson, M., Cormack, A., McRobert, L., \& Underhill, R. (2016). 30 Days Wild: Development and evaluation of a large-scale nature engagement campaign to improve well-being. PLoS ONE, 11, e014977. https://doi.org/10.1371/journal.pone.0149777

Richardson, M., Dobson, J., Abson, D. J., Lumber, R., Hunt, A., Young, R., \& Moorhouse, B. (2020). Applying the pathways to nature connectedness at a societal scale: a leverage points perspective. Ecosystems and People, 16, 387-401. https://doi.org/10.1080/26395916.2020.1844296

Richardson, M., Hunt, A., Hinds, J., Bragg, R., Fido, D., Petronzi, D., Barbett, L., Clitherow, T., \& White, M. (2019). A measure of nature connectedness for children and adults: Validation, performance, and insights. Sustainability, 11, 3250. https://doi.org/10.3390/su11123250

Richardson, M., \& McEwan, K. (2018). 30 Days Wild and the relationships between engagement with nature's beauty, nature connectedness and well-being. Frontiers in Psychology, 9, 1500. https://doi.org/10.3389/fpsyg.2018.01500

Richardson, M., \& Sheffield, D. (2017). Three good things in nature: Noticing nearby nature brings sustained increases in connection with nature. Psyecology, 8, 1-32. https://doi.org/10.1080/21711976.2016.1267136

Ryan, R. M., \& Deci., E. L. (2016). Relationships motivation theory: The self in close relationships. SelfDetermination Theory: Basic psychological needs in motivation, development, and wellness. (pp. 293-316). Guilford Publications. https://doi.org/10.1521/978.14625/28806

Ryan, M. R., Huta, V., \& Deci, E. L. (2008). Living well: A self-determination theory perspective on eudaimonia. Journal of Happiness Studies, 9, 139-170. https://doi.org/10.1007/s10902-006-9023-4

Schultz, P. W. (2001). Assessing the structure of environmental concern: Concern for the self, other people, and the biosphere. Journal of Environmental Psychology, 21, 327-339. https://doi.org/10.1006/jevp.2001.0227

Siebold, D. R., \& McPhee, R. D. (1979). Commonality analysis: A method for decomposing explained variance multiple regression analysis. Human Communication Research, 5, 355-363. https://doi.org/10.1111/j.1468-2958.1979.tb00649.x

Soga, M., Gaston, K. J., Yamaura, Y., Kurisu, K., \& Hanaki, K. (2016). Both direct and indirect vicarious experiences of nature affect children's willingness to conserve biodiversity. International Journal of Environmental Research and Public Health, 13, 529. https://doi.org/10.3390/ijerph3060529

Steel, Z., Marnane, C., Iranpour, C. Chey, T., Jackson, J. W., Patel, V., \& Silove, D. (2014). The global prevalence of common mental disorders: A systematic review and meta-analysis. International Journal of Epidemiology, 43, 476-493. https://doi.org/10.1093/ije/dyu038

Steger, M. F., Frazier, P., \& Oishi, S. (2006). The Meaning in Life Questionnaire: Assessing the presence of and search for meaning in life. Journal of Counseling Psychology, 53, 80-93, https://doi.org/10.1037/0022-016.53.1.80

Steger, M. F., \& Kashdan, T. B. (2013). The unbearable lightness of meaning. Well-being and unstable meaning in life. The Journal of Positive Psychology, 8, 103-115.

https://doi.org/10.1080/17439730.2013.771208 
Steptoe, A., Tsuda, A., Tanaka, Y., \& Wardle, J., (2007). Depressive symptoms, socio-economic background, sense of control, and cultural factors in university students from 23 countries. International Journal of Behavioral Medicine, 14, 97-107. https://doi.org/10.1007/BF03004175

Tanja-Dijkstra, K., Pahl, S., White, M. P., Auvray, M., Stone, R. J., Andrade, J., May, J., Mills, I., \& Moles, D. R. (2018). The soothing sea: A virtual coastal walk can reduce experienced and recollected pain. Environment and Behavior, 50, 599-625. https://doi.org/10.1177/0013916517710077

Tonidandel, S., \& LeBreton, J. M. (2011). Relative importance analysis: A useful supplement to regression analysis. Journal of Business Psychology, 26, 1-9. https://doi.org/10.1007/s10869-010-9204-3

Van den Berg, A. E., Maas, J., Verheij, R. A., \& Groenewegen, P. P. (2010). Green space as a buffer between stressful life events and health. Social Science and Medicine, 70, 1203-1210. https://doi.org/10.1016/j.socscimed.2010.01.002

Veenhoven, R. (1994). World database of happiness: Correlates of happiness. Erasmus University.

Verheij, R., Maas, J., \& Groenewegen, P. P. (2008). Urban-rural health differences and the availability of green space. European Urban and Regional Studies, 15, 307-316. https://doi.org/10.1177/0969776408095107

Verne, P. (2009). Happiness, freedom and control. Journal of Economic Behavior and Organization, 71, 146161. https://doi.org/10.1016/j.jebo.2009.04.008

Waite, L. W., \& Gallagher, M. (2001). The case for marriage: Why married people are happier, healthier, and better off financially. Broadway Books.

Welzel, C., \& Inglehart, R. (2015). Agency, values, and well-being: A human development model. Social Indicators Research, 97, 43-63. https://doi.org/10.1007/s11205-009-9557-z

White, M. P., Alcock. I., Grellier, J., Wheeler, B. W., Hartig, T., Warber, S. L., Bone, A., Depledge, M. H., \& Fleming, L. E. (2019) Spending at least 120 minutes a week in nature is associated with good health and wellbeing. Scientific Reports, 9, 7730.

White, M. P., Yeo, N. L., Vassiljev, P., Lundstedt, R., Wallergård, M., Albin, M., \& Lohmus, M. (2018). A prescription for "nature"-the potential of using virtual nature in therapeutics. Neuropsychiatric Disease and Treatment, 14, 3001-3013. https://doi.org/10.2147/NDT.S19038

WHO: World Health Organization. (2018). Mental health: Strengthening our response. https://www.who.int/news-room/fact-sheets/detail/mental-health-strengthening-our-response

Zelenski, J. M., \& Nisbet, E. K. (2014). Happiness and feeling connected: The distinct role of nature relatedness. Environment and Behavior, 46, 3-23. https://doi.org/10.1177/0013916512451901 